\title{
Application of Post-experience in Practice Teaching of Medical Imaging Technology
}

\author{
Zhigang Qin*, Yao Yang, Zheng Huang, and Miaoxiu Sun \\ Sichuan Vocational College of health and rehabilitation, Zigong, China
}

\begin{abstract}
Early clinical, multi clinical and repeated clinical has always been one of the key contents of practice teaching reform of medical image technology, and also one of the basic requirements of the post-experience reform. Combined with the requirements of national policy and vocational education, medical imaging technology students of our department regularly enter the imaging departments of different levels of hospitals for the post-experience activities through freshmen and sophomores. The results show that this practice teaching activity can cultivate students' clinical thinking of imaging technology, doctor-patient communication ability, practical operation ability and improve self-learning ability, and lay a solid foundation for students ' internship and employment. It is well received by employers and students all the time to cultivate the comprehensive quality of students majoring in imaging technology and systematically understand the clinical situation of the specialty by using post-experience practice teaching. It is worth combining the national policy, the needs of grass-roots employers and the actual situation of the Department to continue the in-depth development and continuous optimization, and effectively promote the cooperation of medical and education, jointly educate people and serve primary health care.
\end{abstract}

\section{Introduction}

The major of medical imaging technology is to cultivate all-round development of morality, intelligence, physique, beauty and labour, with good professional ethics, master the basic theoretical knowledge and professional skills of medical imaging technology, and the ability to engage in imaging examination technology such as general X-ray, CT, MRI, ultrasound, nuclear medicine and radiotherapy[1]. It is a practical subject of medical technology. After several years of research on graduates and employers, it is found that employers and students have very high requirements on students' professional skills before graduation, while higher vocational students have a short time in school and a lot of learning content, which requires everyone to pass the professional skills; And in recent years, the secondary employment rate of students has increased year by year. Therefore, we must make good use of practical teaching, especially the students' post-experience, to solve the problem of students' skills and employment instability.

* Corresponding author:376922096@qq.com 
At present, it has been practised in the hierarchical diagnosis and treatment and the third-party Medical Imaging Centers for many years, but many grassroots central health hospitals feel pressure on the professional skills of new imaging technicians and face challenges[2]. In addition, it is necessary to cultivate medical imaging technology talents with professional and technical skills that can be used at the grassroots level, reduce secondary employment and stabilize employment. The training of medical imaging technology talents must adapt to the needs of the society, combined with the national policy, the needs of employers and the actual situation of the Department, carry out the stage by level post-experience for students, gradually cultivate students' observation ability, imaging technology hands-on ability and doctor-patient communication ability, improve the ability of self-learning, guide students' professional development, and position the future employment direction. The purpose of the post-experience (post recognition and test) in our department is clear, that is to let students have a systematic and preliminary understanding of the daily work, imaging clinical examination, treatment process and diagnosis of imaging-related jobs. After years of practice, exploration, discussion and reform, good results have been achieved.

\section{Before post-experience}

The hospital provides a variety of software and hardware conditions and the most real practical teaching environment in the implementation process of post-experience. And the hospital doctors and technicians have rich experience in the imaging department. Before the post-experience, it needs to be well connected with the science and Education Department of the hospital, and the science and education department needs to be well connected with the corresponding imaging departments. All kinds of documents of post-experience (student syllabus, physician and technician syllabus, assessment and evaluation standards) will be distributed to students, clinical doctors and technicians in advance. The group list of postexperience, contact information of team leaders and experience schedule should be distributed to the corresponding departments of the hospital.

Students go to the post-experience that is, they go to the hospital to recognize the post and try the post, and have the idea of contacting the hospital doctors, technicians and imaging professional equipment. To ensure the safety of students, safety education should be carried out, including the training of sense of hospital, appearance and personal safety. In order not to affect the normal working order of the hospital, the students were divided into several groups and sent to different imaging departments in different hospitals. The outline of post-experience should give students a comprehensive interpretation, mainly to implement the tasks and requirements of students' post-experience. Students must abide by the rules and regulations of the hospital and imaging departments, respect patients and teachers. Efforts to learn professional knowledge and skills, doctor-patient communication and clinical thinking ability.

\section{In the post-experience}

The first post-experience is to recognize the post, and the second one is to test the post. The first time is to fully understand the distribution law of each department and imaging department, the department rules and regulations, the development direction of each imaging department, and learn the content of doctor-patient communication. Based on the first post-experience and the theoretical courses, we can carry out the simple trial of the professional skills that we have learned and will learn under the guidance of the teachers. 
When recognizing the post, the teaching teachers should teach according to the teaching syllabus, job standards, various rules and regulations, and all kinds of protection safety education. During the post-examination, students can operate the simple technology under the guidance of the teacher, mainly including the operation experience of various simple imaging technology, such as DR, CR, MRI and other large equipment. In the process of post-experience teaching, doctor-patient communication, humanistic education and ideological and political education are added. The focus of teaching will be shifted from "knowledge post + test post" to a broader and diversified basic quality of imaging technicians.

Students are required to strictly abide by the rules and regulations of the imaging department, wear white coats and enter the imaging-related departments for observation and study; Take a notebook with you, record the observed image related equipment and operation process, record the problems, and wait for the teacher to consult in his spare time. Don't express your opinion in front of the patient. Let students with the desire to learn and understand all kinds of professional knowledge and skills. Because of the imaging equipment, examination technology, operation skills and doctor-patient communication, they consulted the relevant necessary literature on the Internet and made comprehensive thinking.

Clinical technicians and doctors provide clinical imaging equipment and rich imaging data to explain and guide these students. Even some classic cases of doctor-patient communication will benefit students for life. Through a series of real clinical activities such as observation, operation and contact with patients, students can be familiar with the hospital environment, contact with patients, understand medical ethics and experience the basic examination process. According to the student's knowledge level and teaching syllabus, the teachers should ask questions and give guidance, so that the students can have a correct understanding of medical imaging technology. At the same time, during the probation week, these teachers always answer the questions raised by the students.

\section{After the post-experience}

The score of post-experience is composed of student experience report score, clinician and technician score, unified examination score after experience and PPT report score of each group. First, hand in the post-experience record book and score it; The second is to conduct a questionnaire survey and anonymous survey on students' post-experience; After two different periods of post-experience of the same students in 2018 and 2019, we conducted an intention questionnaire survey. The following conclusions are obtained (Table 1). The first job experience: students have a strong interest; It can help students understand their development direction correctly; It can improve students' learning enthusiasm. Second job experience: easy to make students tired, cannot get the desired effect; The content of professional courses are not enough. When students spend a week experience at this time, they can't test all positions; Generally speaking, students' experience level is not as good as that of the first time because the theory is not deep enough; Students in the second job experience is not as interested as the first, so we should strengthen the assessment and refine the assessment details. Third, carry out post-experience seminars, exchange the problems encountered by students and teachers in post-experience, and adjust the next postexperience appropriately. 


\section{Discussions}

The post-experience of students majoring in imaging technology in the clinical imaging department is an important practical teaching method in the whole medical imaging education, which needs continuous improvement and optimization. Its purpose is not only to help students understand the nature of each post of imaging, but also to cultivate students' working thinking of imaging technology and the ability to flexibly use the learned knowledge, to make students learn and use flexibly and improve their comprehensive quality [3]. To carry out the post-experience activities of imaging technology, it is necessary to continuously improve, promote students' autonomous learning, formulate their life goals, be able to go to the grass-roots level and be willing to go to the grass-roots level for employment, to make students understand the current situation and work hard.

Table 1. Students' evaluation on the effect of post-experience week

\begin{tabular}{|c|c|c|c|}
\hline & & \multicolumn{2}{|c|}{ percentage } \\
\cline { 2 - 4 } Evaluation content & option & $\begin{array}{c}\text { The second } \\
\text { half of } \\
\text { freshman } \\
\text { year }\end{array}$ & $\begin{array}{c}\text { The first } \\
\text { half of } \\
\text { sophomore } \\
\text { year }\end{array}$ \\
\hline Understanding of imaging & & $91 \%$ & $98 \%$ \\
technology profession & Very high & $9 \%$ & $2 \%$ \\
\hline Have you learned anything & Commonly & 0 & $0 \%$ \\
in each imaging & No & $74 \%$ & $30 \%$ \\
department & yes & $23 \%$ & $40 \%$ \\
& Just a little bit & $3 \%$ & $30 \%$ \\
\hline On your current learning & waiver & $4 \%$ & $20 \%$ \\
(multiple choice) & Increase the burden & $75 \%$ & $1 \%$ \\
& broaden one's horizon & $10 \%$ & $40 \%$ \\
It didn't help much & $83 \%$ & $30 \%$ \\
\hline For your future study and & It helps & & $10 \%$ \\
work & It's very helpful & $93 \%$ & $20 \%$ \\
\hline The necessity of post- & & $6 \%$ & $60 \%$ \\
experience week & It helps a lot & $1 \%$ & $20 \%$ \\
\hline After the post-experience, & It helps & $98 \%$ & $20 \%$ \\
is it necessary to hold a & It didn't help much & $1 \%$ & $10 \%$ \\
forum & It is necessary to carry out & $1 \%$ & $70 \%$ \\
\hline
\end{tabular}

\subsection{Promote the improvement of students' professional quality.}

Make good use of all kinds of resources in a practice teaching position, deepen the understanding and consolidation of theoretical knowledge, and improve clinical thinking ability and practical ability. Using high-end equipment in the imaging department to communicate with patients to stimulate self-learning and learning enthusiasm; Through the post-experience, the students strengthened the process of imaging technology and the ability to communicate with patients; The students' sense of unity and cooperation and sense of responsibility were enhanced to arouse their love for patients and medical equipment; At the same time, it mobilized the students' learning initiative, cultivated their 
ability to find, put forward, analyze and solve problems, and carried out beneficial exploration for the cultivation of high-quality innovative medical talents [4].

\subsection{Establish a better post-experience system.}

Continue to optimize and improve the expansion of post-experience, aiming at the shortcomings of the second unified post-experience activities and students' requirements. Work out the professional curriculum post-experience plan, purpose, content, form, location and requirements. To consolidate and improve the professional ability, the time and teachers should be selected for the post-test. To ensure the quality of post-experience, it is necessary to avoid a large number of students to practice a kind of imaging technology in a hospital in a short time. The post-experience should be put to the primary medical and health institutions for a certain period. To solve the problem of the continuous increase of the secondary employment rate. It is necessary to connect the students' abilities with the posts of primary medical institutions. So that students can work at the grass-roots level, and stay. Therefore, the Department signed an agreement with the central health center near the college to provide students with the conditions of the grassroots health center under the post-experience, To understand the future employment environment in advance. This arrangement reflects the docking of post and skill demand, employment demand and training orientation. Doctors and technicians from these units guide students' professional development and employment needs.

\subsection{Continue to improve the evaluation system.}

Assessment and evaluation of teaching teachers and post-experience students is an important guarantee to promote post-experience. To achieve the end of a post-experience project, the post-experience assessment and evaluation can be carried out. Timely analysis and summary, and the next revision, the establishment of real-time feedback mechanism. To promote students' active learning, teachers take teaching seriously and improve their ability.

\subsection{Establish the homogenization of post-experience digital resources.}

According to the training requirements of the talent training plan, do a good job in the postexperience teaching manual and promote the use of the manual. No matter which hospital students go to, they can learn the job-related content, the same standard.

\subsection{Follow the rules and do not pull out the seedlings}

There are some misunderstandings in the post-experience, which also need to be paid attention to. We should follow the students' learning rules, and can't pull out the seedlings. Medical imaging technology major is a very rigorous medical technology, which must be done to better play the role of experience. It violates the post-experience rule of "knowledge post + trial post + actual post". The first time I know the post, I try the post first, which leads to a great psychological gap of students, and there is no good guidance, so that students' confidence in the major is easy to lose. So in the post-experience, we must follow the process of the first simple than complex, the first general then comprehensive, the first master then proficient. In the process of post-experience, teachers don't complete the post-experience manual according to the requirements, but speak it at will, which leads to students lose their complete knowledge. 


\section{Conclusions}

It is very necessary to add post experience in the practical teaching system of medical imaging technology specialty. In order to implement the purpose of post-experience in the second post-experience, we should reasonably arrange time and implement teaching tasks. In a word, we should strengthen the cooperation between colleges and hospitals, realize the sharing of resources, the cultivation of talents, the cultivation of doctors and students, and realize the mutual benefit of teaching and learning. Schools, hospitals, doctors and students all become the beneficiaries of post-experience. Finally, the common development of schools and hospitals will be realized, benefiting schools, hospitals and patients.

\section{References}

1. Huang Yangxi, Lei Ming, Dai Ying, Wang cuiqiong. Discussion on the current situation and training of medical imaging technology talents [a]. New era of Education (November 2015, Volume 6) [C]:, 2015:1

2. Zhong Yi. Exploration on teaching mode and reform of medical imaging technology [J]. Contemporary medicine, 2009,24:164 + 17

3. Lei Yuanyi, Feng Xia. Past, present and future of medical imaging technology and equipment [J]. Medical equipment information, 2004,08:30-32

4. Wang Xiaoyan, Wang Pengcheng, Song Li, Qiu Jianfeng, Xie Jindong. Thinking on training high quality talents of medical imaging technology in China [J]. Chinese Journal of medical physics, 2013,03:4212-4214 